\title{
Perioperative Risk Adjustment for Total Shoulder Arthroplasty: Are Simple Clinically Driven Models Sufficient?
}

\author{
David N. Bernstein MA, Aakash Keswani BA, David Ring MD, PhD
}

Published online: 30 November 2016

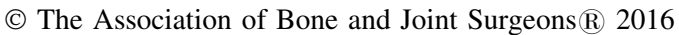

\begin{abstract}
Background There is growing interest in value-based health care in the United States. Statistical analysis of large databases can inform us of the factors associated with and the probability of adverse events and unplanned readmissions that diminish quality and add expense. For example, increased operating time and high blood urea nitrogen
\end{abstract}

One of the authors (DR) received royalties from Tornier/Wright Medical (Memphis, TN, USA) for elbow plates in the amount of $<$ USD 10,000/year and Skeletal Dynamics (Miami, FL, USA) for an internal joint stabilizer elbow; received research grant support from Skeletal Dynamics in the amount of USD 50,000; is Deputy Editor for Hand and Wrist and Journal of Orthopaedic Trauma as a volunteer; is Deputy Editor for Hand and Wrist and Clinical Orthopaedics and Related Research ${ }^{\mathbb{R}}$; and received honoraria from meetings from $\mathrm{AO}$ North America, AO International, and various hospitals and universities.

All ICMJE Conflict of Interest Forms for authors and Clinical Orthopaedics and Related Research ${ }^{\mathbb{R}}$ editors and board members are on file with the publication and can be viewed on request.

The American College of Surgeons National Surgical Quality Improvement Program and the hospitals participating in the ACS NSQIP are the source of the data used herein; they have not verified and are not responsible for the statistical validity of the data analysis or the conclusions derived by the authors.

This work was performed at the Department of Surgery and Perioperative Care, Dell Medical School, The University of Texas, Austin, TX, USA.

Electronic supplementary material The online version of this article (doi:10.1007/s11999-016-5147-y) contains supplementary material, which is available to authorized users.

D. N. Bernstein

University of Rochester School of Medicine \& Dentistry,

Rochester, NY, USA

A. Keswani

Department of Orthopaedics, Mount Sinai Hospital, New York, NY, USA
(BUN) are associated with adverse events, whereas patients on antihypertensive medications were more likely to have an unplanned readmission. Many surgeons rely on their knowledge and intuition when assessing the risk of a procedure. Comparing clinically driven with statistically derived risk models of total shoulder arthroplasty (TSA) offers insight into potential gaps between common practice and evidence-based medicine.

Questions/Purposes (1) Does a statistically driven model better explain the variation in unplanned readmission within 30 days of discharge when compared with an a priori five-variable model selected based on expert orthopaedic surgeon opinion? (2) Does a statistically driven model better explain the variation in adverse events within 30 days of discharge when compared with an a priori fivevariable model selected based on expert orthopaedic surgeon opinion?

Methods Current Procedural Terminology codes were used to identify 4030 individuals older than 17 years of age who had TSA in which osteoarthritis was the primary etiology. A logistic regression model for adverse event and unplanned readmission within 30 days was constructed using (1) five variables chosen a priori based on clinic expertise (age, American Society of Anesthesiologists classification $\geq 3$, body mass index, smoking status, and diabetes mellitus); and (2) by entering all variables with $p$ $<0.10$ in bivariate analysis. We then excluded 870 patients (22\%) based on preoperative factors felt to make large

\footnotetext{
D. Ring $(\bowtie)$

Department of Surgery and Perioperative Care, Dell Medical School, The University of Texas at Austin, 1400 Barbara Jordan Boulevard, Suite 2.834, MC: R1800, Austin, TX 78723, USA e-mail: david.ring@austin.utexas.edu
} 
discretionary surgery unwise to focus our research on appropriate procedures. Infirm patients have more pressing needs than alleviation of shoulder pain and stiffness. Among the remaining 3160 patients, logistic regression models for adverse event and unplanned readmission within 30 days were constructed in a similar manner to the complete models. The five a priori risk factors used in each model based on clinical expertise were selected by consensus of an expert orthopaedic surgeon panel.

Results When patients unfit for discretionary surgery were excluded, the clinically driven model found no risk factors and accounted for $1.4 \%$ of the variation in unplanned readmission. In contrast, the statistically driven model explained $4.6 \%$ of the variation and found operating time (hours) (odds ratio [OR], 1.26; 95\% confidence interval [CI], 1.04-1.53) and hypertension requiring medications (OR, 1.95; 95\% CI, 1.01-3.76) were associated with unplanned readmission accounting for all other factors. However, neither the clinically driven model (pseudo $\mathrm{R}^{2}, 1.4 \%$ ) nor statistically driven model (pseudo $\mathrm{R}^{2}, 4.6 \%$ ) provided much explanatory power. When patients unfit for discretionary surgery were excluded, no factors in the clinically driven model were significant and the model accounted for $0.95 \%$ of the variation in adverse events. In the statistically driven model, age (OR, 1.03; 95\% CI, 1.01-1.06), men (OR, 1.64; 95\% CI, 1.05-2.57), operating time (hours) (OR, 1.27; 95\% CI, 1.07-1.52), and high BUN (OR, 3.12; 95\% CI, 1.35-7.21) were associated with adverse events when accounting for all other factors, explaining $3.3 \%$ of the variation. However, neither the clinically driven model (pseudo $\mathrm{R}^{2}, 0.95 \%$ ) nor the statistically driven model (pseudo $\mathrm{R}^{2}, 3.3 \%$ ) provided much explanatory power.

Conclusions The observation that a statistically derived risk model performs better than a clinically driven model affirms the value of research based on large databases, although the models derived need to be tested prospectively. Clinical Relevance Clinicians can utilize our results to understand that clinician intuition may not always offer the best risk adjustment and that factors impacting TSA unplanned readmission and adverse events may be best derived from large data sets. However, because current analyses explain limited variation in outcomes, future studies might look to better define what factors drive the variation in unplanned readmission and adverse events.

\section{Introduction}

The US healthcare system is beginning to shift from a feefor-service to a value-based model, in which value is defined as an improvement in an outcome of interest per healthcare dollar spent [20]. Consequently, there is increasing attention on factors associated with adverse events or unplanned readmission. These represent an increased financial burden and avoidable use of limited resources [4, 13, 24]. Alternative payment models such as Medicare's Bundled Payment for Care Improvement initiative and Comprehensive Care for Joint Replacement, which provide fixed reimbursement for an entire episode of care (such as THA and TKA and, more recently, hip fracture), are helping to align payer and provider financial incentives toward minimizing complications [9].

Surgeons are responsible for understanding the risk factors that lead to adverse events and unplanned readmissions, ensuring that modifiable factors are optimized before surgery and identifying factors that make discretionary surgery unwise. Studies have assessed the impact of risk factors on patient adverse events and unplanned readmission after hip and knee arthroplasties [7, 8, 19, 23], elbow arthroplasty [10, 17], and shoulder arthroplasty $[3,18,28]$, but surgeons seem to use their judgment rather than screening tools based on evidence $[6,25]$. A study comparing intuitive risk factors with those identified by an analysis of a large database might help surgeons understand the limits of expert impressions and daily judgment. An awareness of the limits of expert judgment could make a preoperative screening algorithm for appropriateness and risk modification an appealing part of perioperative care.

We therefore asked: (1) Does a statistically driven model better explain the variation in unplanned readmission within 30 days of discharge when compared with an a priori fivevariable model selected based on expert orthopaedic surgeon opinion? (2) Does a statistically driven model better explain the variation in adverse events within 30 days of discharge when compared with an a priori five-variable model selected based on expert orthopaedic surgeon opinion?

\section{Materials and Methods}

Data from the American College of Surgeons National Surgical Quality Improvement Program (ACS NSQIP) from 2011 to 2014 was used in this study [1]. The annual data sets document all inpatient surgical procedures, of which orthopaedic surgery is a subset. Currently, 765 US hospitals participate in the ACS NSQIP [2]. Current Procedural Terminology (CPT) codes were used to identify adult (aged 18 years and older) individuals within the data set who underwent primary total shoulder arthroplasty (TSA) or reverse shoulder arthroplasty (CPT 23472) and had a diagnosis of osteoarthritis (CPT 715.XX) as the primary etiology. Patients with revision shoulder arthroplasty were excluded. The NSQIP was chosen because its data are based on expert review of the medical record rather than from administrative or billing records. 
A total of 4030 patients met the initial inclusion criteria. There was a notable number of patients who were infirm or had a major metabolic deviation that would seem to make discretionary surgery unwise. Appropriateness in patient selection is a key aspect of safe and effective discretionary surgery. By limiting the analysis to patients meeting medical appropriateness criteria, we obtain data more applicable to a preoperative assessment protocol rather than just documenting the expected results of operating on patients who are infirm or unstable. Based on the following criteria that we felt would make a substantial, discretionary, quality-of-life surgery such as TSA unwise, 870 of 4030 patients $(22 \%)$ were excluded from the data set: American Society of Anesthesiologists (ASA) physical status classification $4(\mathrm{n}=91)$; inpatient transfer from another facility $(\mathrm{n}=20)$; dyspnea with mild exertion $(\mathrm{n}=$ $245)$; dyspnea at rest $(\mathrm{n}=14)$; open wound or infection $(\mathrm{n}=$ $22)$; need for transfusion preoperatively $(n=5)$; congestive heart failure $(\mathrm{n}=13)$; disseminated cancer $(\mathrm{n}=2)$; dialysisdependent $(\mathrm{n}=19)$; recent weight loss $(>10 \%$ in the last 6 months) $(\mathrm{n}=6)$; renal failure $(\mathrm{n}=4)$; functional status (fully dependent) $(\mathrm{n}=3)$; high white blood cell count $(>$ $10,000 / \mu \mathrm{L})(\mathrm{n}=252)$; low hematocrit $(<30 \%)(\mathrm{n}=30)$; high bilirubin $(>1.9 \mathrm{mg} / \mathrm{dL})(\mathrm{n}=6)$; low albumin $(<3.4 \mathrm{~g} /$ dL) $(n=60)$; systemic inflammatory response syndrome $(\mathrm{n}=0)$; sepsis $(\mathrm{n}=0)$; septic shock $(\mathrm{n}=0)$; low sodium $(<$ $135 \mathrm{mEq} / \mathrm{L})(\mathrm{n}=219)$; high sodium $(>145 \mathrm{mEq} / \mathrm{L})$ $(n=43)$; wound classification: contaminated or dirty/infected $(\mathrm{n}=15)$; and ascites $(\mathrm{n}=1)$. Patients may have had more than one risk factor that made discretionary surgery unwise.

We identified 3160 surgical procedures matching the full inclusion criteria. The average patient age was 69 years (SD, 9.5 years) with women accounting for just over half of the patients $(51 \%)$ (Table 1$)$. The average body mass index (BMI) was $31 \mathrm{~kg} / \mathrm{m}^{2}\left(\mathrm{SD}, 6.7 \mathrm{~kg} / \mathrm{m}^{2}\right)$. Nearly two-thirds of the patients $(65 \%)$ had hypertension requiring medications.

\section{Statistical Analysis}

The two dependent variables of interest were (1) unplanned readmission and (2) adverse event within 30 days of discharge after a TSA. Because our dependent variables were dichotomous, bivariate logistic regression was conducted for all independent variables (the risk factors we considered) to determine odds ratios and significance.

After the bivariate analyses, four risk-adjustment models were developed for this study. Two models were created with the data containing all patients and two models were created with the patients unfit for elective surgery excluded. In each set of models, one was based off of an a priori selection of five risk factors that a panel of orthopaedic surgeons came to consensus on. The five risk factors selected for the all patients clinically driven model were: age, ASA classification $\geq 3$, BMI, present smoker, and diabetes mellitus. The five risk factors selected for the appropriate patient clinically driven model were: age, ASA classification 3, BMI, present smoker, and diabetes mellitus. Each full model used the results of bivariate logistic regression to determine which risk factors were to be included in the multivariable regression (Table 2). Variables with odds ratios that were significant at the $\mathrm{p}<0.10$ level were included. For all four models, pseudo $\mathrm{R}^{2}$ values were reported as well as for each risk factor. The area under the receiver operating characteristic curve (c-statistic) and Hosmer-Lemeshow statistic were calculated to ensure appropriate model performance. A c-statistic of 0.5 indicates the model is no better than chance, whereas a c-statistic of 1.0 indicates the model perfectly predicts the outcome.

A post hoc power analysis based on a chi square test determined that 3160 patients provided $99 \%$ power to detect a variable explaining $30 \%$ of the variability in adverse events or unplanned readmission with an $\alpha$ of 0.05 .

\section{Results}

The statistically driven model (pseudo $\mathrm{R}^{2}=0.046$ ) better explained the variation in unplanned readmission within 30 days of discharge after a TSA compared with the clinically driven model (pseudo $\mathrm{R}^{2}=0.014$ ) (Table 3). The statistically driven model included eight factors: operating time (hours) (odds ratio [OR], 1.26; 95\% confidence interval [CI], 1.04-1.53); hypertension requiring medications (OR, 1.95; 95\% CI, 1.01-3.76); age (OR, 1.02; 95\% CI, 0.991.05); men (OR, 1.60; 95\% CI, 0.94-2.71); ASA classification 3 (OR, 1.21; 95\% CI, 0.71-2.04); high blood urea nitrogen (> $30 \mathrm{mg} / \mathrm{dL})(\mathrm{OR}, 2.13 ; 95 \% \mathrm{CI}, 0.78-5.77)$; high creatinine $(1.3 \mathrm{mg} / \mathrm{dL})(\mathrm{OR}, 1.30$; $95 \% \mathrm{CI}, 0.54$ $3.16)$; and low platelets $(<150,000 / \mu \mathrm{L})(\mathrm{OR}, 2.14 ; 95 \%$ CI, 0.98-4.65). The statistically driven model performed better than the clinically driven model for unplanned readmission (c-statistic: 0.64 versus 0.61 ). The statistically driven model with all patients (pseudo $\mathrm{R}^{2}=0.046$; $\mathrm{c}$ statistic, 0.68), including those deemed unfit for elective surgery, explained more of the variation and performed better than the clinically driven model (pseudo $\mathrm{R}^{2}=0.018$; c-statistic, 0.63) (Appendix 1 [Supplemental materials are available with the online version of $\operatorname{CORR}^{\mathbb{R}}$.]). In the clinically driven all patients model, age (OR, $1.03 ; 95 \% \mathrm{CI}$, 1.01-1.06) and ASA classification $\geq 3$ (OR, 1.68; 95\% CI, 1.07-2.63) were significantly associated with unplanned readmission. In the statistically driven all patients model, high sodium ( $>145 \mathrm{mEq} / \mathrm{L})(\mathrm{OR}, 6.73 ; 95 \% \mathrm{CI}, 2.53-$ 17.93), age (OR, 1.03; 95\% CI, 1.01-1.05), operating time 
Table 1. Patient characteristics, 2011-2014

\begin{tabular}{|c|c|c|}
\hline \multirow[b]{3}{*}{ Characteristic } & \multicolumn{2}{|l|}{ TSA } \\
\hline & \multicolumn{2}{|l|}{$(\mathrm{N}=3160)$} \\
\hline & $\begin{array}{l}\text { Number of } \\
\text { Patients }\end{array}$ & Percent \\
\hline \multicolumn{3}{|l|}{ Demographics } \\
\hline Age (years)* (mean $\pm \mathrm{SD})$ & $69 \pm 9.5$ & - \\
\hline \multicolumn{3}{|l|}{ Sex } \\
\hline Men & 1540 & 49 \\
\hline Women & 1620 & 51 \\
\hline \multicolumn{3}{|l|}{ ASA classification } \\
\hline 1 or 2 & 1711 & 54 \\
\hline 3 & 1449 & 46 \\
\hline \multicolumn{3}{|l|}{ Comorbid conditions } \\
\hline BMI $\left(\mathrm{kg} / \mathrm{m}^{2}\right)($ mean $\pm \mathrm{SD})$ & $31 \pm 6.7$ & - \\
\hline Hypertension requiring medications & 2038 & 65 \\
\hline Bleeding disorder & 78 & 2.5 \\
\hline History of smoking & 257 & 8.1 \\
\hline COPD & 106 & 3.4 \\
\hline Diabetes mellitus & 441 & 14 \\
\hline Corticosteroid use & 103 & 3.3 \\
\hline Functional status (partially dependent) & 30 & 1.0 \\
\hline \multicolumn{3}{|c|}{ Laboratory results within 90 days preoperatively (\%) } \\
\hline Low WBC count $(<4500 / \mu \mathrm{L})$ & 182 & 5.8 \\
\hline Low platelets $(<150,000 / \mu \mathrm{L})$ & 159 & 5.0 \\
\hline High INR (> 1.1) & 112 & 3.5 \\
\hline High creatinine $(>1.3 \mathrm{mg} / \mathrm{dL})$ & 174 & 5.5 \\
\hline High blood urea nitrogen $(>30 \mathrm{mg} / \mathrm{dL})$ & 103 & 3.3 \\
\hline \multicolumn{3}{|l|}{ Intraoperative variables } \\
\hline Regional anesthesia & 127 & 4.0 \\
\hline Operating time (hours) (mean $\pm \mathrm{SD}$ ) & $1.95 \pm 0.81$ & - \\
\hline \multicolumn{3}{|l|}{ Outcomes, 30-day } \\
\hline Adverse event rate & 87 & 2.8 \\
\hline Unplanned readmission & 64 & 2.0 \\
\hline \multicolumn{3}{|l|}{ Outcomes, specific } \\
\hline \multicolumn{3}{|l|}{ Adverse events, 30 -day } \\
\hline Urinary tract infection & 20 & 0.6 \\
\hline Pneumonia & 8 & 0.3 \\
\hline Sepsis & 2 & 0.06 \\
\hline Septic shock & - & - \\
\hline Unplanned intubation & 1 & 0.03 \\
\hline Myocardial infarction & 4 & 0.1 \\
\hline \multicolumn{3}{|l|}{ Surgical site infection } \\
\hline Superficial & 4 & 0.1 \\
\hline Deep wound & 2 & 0.06 \\
\hline Organ space & 1 & 0.03 \\
\hline Deep vein thrombosis & 15 & 0.5 \\
\hline Cardiac arrest requiring $\mathrm{CPR}$ & - & - \\
\hline On ventilator $>48$ hours & 1 & 0.03 \\
\hline Renal insufficiency & & \\
\hline
\end{tabular}

Table 1. continued

\begin{tabular}{|c|c|c|}
\hline \multirow[b]{3}{*}{ Characteristic } & \multicolumn{2}{|l|}{ TSA } \\
\hline & \multicolumn{2}{|l|}{$(\mathrm{N}=3160)$} \\
\hline & $\begin{array}{l}\text { Number of } \\
\text { Patients }\end{array}$ & Percent \\
\hline Progressive & 2 & 0.06 \\
\hline Acute & - & - \\
\hline Cerebrovascular accident & 2 & 0.06 \\
\hline Wound dehiscence & 3 & 0.09 \\
\hline Return to OR & 30 & 1.0 \\
\hline
\end{tabular}

* Patients requiring multiple adverse events only count once in the overall rate; TSA $=$ total shoulder arthroplasty; ASA $=$ American Society of Anesthesiologists; $\mathrm{BMI}=$ body mass index; $\mathrm{COPD}=$ chronic obstructive pulmonary disease; $\mathrm{WBC}=$ white blood cell count; INR = international normalized ratio; $\mathrm{CPR}=$ cardiopulmonary resuscitation; $\mathrm{OR}=$ operating room.

(hours) (OR, 1.25; 95\% CI, 1.03-1.51), and low sodium (< $135 \mathrm{mEq} / \mathrm{L})(\mathrm{OR}, 2.01$; 95\% CI, 1.02-3.98) were associated with unplanned readmission.

The statistically driven model (pseudo $\mathrm{R}^{2}=0.033$ ) better explained the variation in adverse events within 30 days postdischarge than the clinically driven model (pseudo $\mathrm{R}^{2}=0.0095$ ). The statistically driven model included six factors: age (OR, 1.03; 95\% CI, 1.01-1.06); men (OR, 1.64; 95\% CI, 1.05-2.57); operating time (hours) (OR, 1.27; 95\% CI, 1.07-1.52); high blood urea nitrogen $(>30 \mathrm{mg} / \mathrm{dL})(\mathrm{OR}, 3.12 ; 95 \% \mathrm{CI}, 1.35-7.21)$; bleeding disorder (OR, 2.25; 95\% CI, 0.87-5.82); and high creatinine $(1.3 \mathrm{mg} / \mathrm{dL})(\mathrm{OR}, 0.98 ; 95 \% \mathrm{CI}, 0.42-2.26)$. The statistically driven model with all patients (pseudo $\mathrm{R}^{2}=$ 0.061; c-statistic, 0.69), including those deemed unfit for elective surgery, explained more of the variation and performed better than the clinically driven model (pseudo $\mathrm{R}^{2}=$ 0.017; c-statistic, 0.62) (Appendix 2 [Supplemental materials are available with the online version of $C O R R^{\circledR}$.]). In the clinically driven all patients model, age (OR, 1.04; $95 \%$ CI, 1.01-1.06) was significantly associated with adverse events. In the statistically driven all patients model, high sodium (> $145 \mathrm{mEq} / \mathrm{L})(\mathrm{OR}, 8.02$; 95\% CI, 3.53-18.20), high blood urea nitrogen $(>30 \mathrm{mg} / \mathrm{dL})(\mathrm{OR}, 2.96 ; 95 \% \mathrm{CI}$, 1.50-5.82), age (OR, 1.03; 95\% CI, 1.01-1.05), and operating time (hours) (OR, 1.25; 95\% CI, 1.05-1.48) were associated with adverse events.

\section{Discussion}

There is growing incidence of upper extremity procedures in the United States [14]. As shown by Virani et al. [27], adverse events after TSA can cost an average of USD 
Table 2. Bivariate analysis of risk factors for adverse events or unplanned readmission

\begin{tabular}{|c|c|c|c|c|}
\hline \multirow[t]{3}{*}{ Outcome/risk factor } & \multicolumn{2}{|l|}{ TSA and adverse event } & \multicolumn{2}{|c|}{ TSA and unplanned readmission } \\
\hline & \multicolumn{2}{|l|}{$(\mathrm{N}=3160)$} & \multicolumn{2}{|l|}{$(\mathrm{N}=3160)$} \\
\hline & Odds ratio $(95 \% \mathrm{CI})$ & $\mathrm{p}$ value & Odds ratio $(95 \% \mathrm{CI})$ & $\mathrm{p}$ value \\
\hline \multicolumn{5}{|l|}{ Demographics } \\
\hline Age (years) & $1.03(1.00-1.05)$ & 0.026 & $1.03(1.00-1.06)$ & 0.039 \\
\hline Men & $1.58(1.03-2.44)$ & 0.038 & $1.66(1.00-2.75)$ & 0.051 \\
\hline \multicolumn{5}{|l|}{ ASA classification } \\
\hline 3 & $1.34(0.87-2.05)$ & 0.18 & $1.63(0.99-2.70)$ & 0.055 \\
\hline \multicolumn{5}{|l|}{ Comorbid conditions } \\
\hline BMI $\left(\mathrm{kg} / \mathrm{m}^{2}\right)$ & $0.99(0.96-1.02)$ & 0.42 & $0.99(0.95-1.03)$ & 0.57 \\
\hline Hypertension requiring medications & $1.30(0.82-2.07)$ & 0.27 & $2.42(1.29-4.56)$ & 0.006 \\
\hline Bleeding disorder & $2.51(0.99-6.37)$ & 0.053 & $1.98(0.61-6.46)$ & 0.26 \\
\hline History of smoking & $1.15(0.55-2.40)$ & 0.71 & $1.40(0.63-3.10)$ & 0.41 \\
\hline COPD & $1.40(0.51-3.90)$ & 0.52 & $0.93(0.22-3.85)$ & 0.92 \\
\hline Diabetes mellitus & $1.29(0.74-2.28)$ & 0.37 & $1.29(0.67-2.48)$ & 0.45 \\
\hline Corticosteroid use & $0.69(0.17-2.85)$ & 0.61 & - & - \\
\hline Functional status (partially dependent) & - & - & - & - \\
\hline \multicolumn{5}{|l|}{ Laboratory results within 90 days preop. (\%) } \\
\hline Low WBC count & $0.78(0.28-2.16)$ & 0.64 & $1.09(0.39-3.04)$ & 0.87 \\
\hline \multicolumn{5}{|l|}{$(<4500 / \mu \mathrm{L})$} \\
\hline Low platelets & $1.16(0.46-2.89)$ & 0.76 & $2.79(1.30-5.95)$ & 0.008 \\
\hline \multicolumn{5}{|l|}{$(<150,000 / \mu \mathrm{L})$} \\
\hline High INR $(>1.1)$ & $1.69(0.67-4.25)$ & 0.27 & $0.88(0.21-3.63)$ & 0.86 \\
\hline High creatinine & $2.03(1.00-4.13)$ & 0.049 & $2.52(1.18-5.38)$ & 0.017 \\
\hline \multicolumn{5}{|l|}{$(>1.3 \mathrm{mg} / \mathrm{dL})$} \\
\hline High blood urea nitrogen & $3.66(1.78-7.51)$ & $<0.001$ & $3.20(1.35-7.59)$ & 0.008 \\
\hline \multicolumn{5}{|l|}{$(>30 \mathrm{mg} / \mathrm{dL})$} \\
\hline \multicolumn{5}{|l|}{ Intraoperative variables } \\
\hline Regional anesthesia & $0.27(0.04-1.97)$ & 0.20 & - & - \\
\hline Operating time (hours) & $1.25(1.05-1.47)$ & 0.010 & $1.25(1.04-1.50)$ & 0.015 \\
\hline
\end{tabular}

$\mathrm{TSA}=$ total shoulder arthroplasty; $\mathrm{CI}=$ confidence interval; ASA = American Society of Anesthesiologists; $\mathrm{BMI}=$ body mass index; COPD = chronic obstructive pulmonary disease; $\mathrm{WBC}=$ white blood cell; INR $=$ international normalized ratio.

14,676. In an era focused on improving surgical quality and decreasing costs, the importance of adequate risk stratification approaches in the selection and management of patients considering TSA is important. As noted by several authors, although many randomized controlled trials and retrospective case-control studies have identified a number of risk factors for complications after TSA, orthopaedic surgeons seem to utilize experience and clinical intuition rather than statistically driven models as a care-redesign strategy [21, 26]. To better understand the gap (if any) between risk stratification based on clinical experience versus data-driven models, we compared the predictive ability of an a priori determined risk model (total of five variables) based on expert orthopaedic surgeon opinion and a statistically driven model (based on a large, nationally representative data set) with respect to unplanned readmission and severe adverse events within 30 days postdischarge after TSA.

Our study results have some limitations. First, we utilized an a priori clinically driven model of only five variables. We believe these to be the most intuitive risk factors based on consensus of a panel of experienced orthopaedic surgeons; however, we acknowledge that not all orthopaedic surgeons would agree. Second, 22\% of patients were inappropriate for TSA-based comorbidities that we felt made it unwise for the patient to have a discretionary surgical procedure. We omitted these patients because we felt a two-step process would better inform daily practice: (1) assess patients for appropriateness; and (2) assess risk factors among appropriate patients. It is 
Table 3. Factors independently associated with an unplanned readmission without inappropriate patients

Model: Unplanned readmission selected a priori by clinical expert opinion (logistic regression)

\begin{tabular}{|c|c|c|c|c|c|}
\hline $\begin{array}{l}\text { Area under the receiver operating characteristic curve (c-statistic) } \\
\text { Pseudo } \mathrm{R}^{2} \\
\text { Hosmer-Lemeshow test } \\
\text { Characteristic }\end{array}$ & $\begin{array}{l}0.61 \\
0.014 \\
0.73 \\
\text { Odds ratio }\end{array}$ & Lower & Upper & $\mathrm{p}$ value & Pseudo $\mathrm{R}^{2}$ (bivariate) \\
\hline Age & 1.03 & 1.00 & 1.06 & 0.068 & 0.007 \\
\hline ASA classification 3 & 1.48 & 0.87 & 2.51 & 0.14 & 0.006 \\
\hline BMI & 0.99 & 0.95 & 1.03 & 0.61 & 0.0005 \\
\hline Present smoker & 1.72 & 0.75 & 3.96 & 0.20 & 0.001 \\
\hline Diabetes mellitus & 1.18 & 0.60 & 2.34 & 0.63 & 0.0009 \\
\hline
\end{tabular}

Model: Unplanned readmission characteristics $<0.10$ in bivariate analysis (logistic regression)

\begin{tabular}{|c|c|c|c|c|c|}
\hline $\begin{array}{l}\text { Area under the receiver operating characteristic curve (c-statistic) } \\
\text { Pseudo } \mathrm{R}^{2} \\
\text { Hosmer-Lemeshow test } \\
\text { Characteristic }\end{array}$ & $\begin{array}{l}0.64 \\
0.046 \\
0.71 \\
\text { Odds ratio }\end{array}$ & Lower & Upper & $\mathrm{p}$ value & Pseudo $R^{2}$ (bivariate) \\
\hline Operating time (hours) & 1.26 & 1.04 & 1.53 & 0.016 & 0.0068 \\
\hline Hypertension requiring medications & 1.95 & 1.01 & 3.76 & 0.046 & 0.014 \\
\hline Age & 1.02 & 0.99 & 1.05 & 0.12 & 0.0070 \\
\hline Men & 1.60 & 0.94 & 2.71 & 0.08 & 0.0063 \\
\hline ASA classification 3 & 1.21 & 0.71 & 2.04 & 0.48 & 0.0060 \\
\hline High blood urea nitrogen $(>30 \mathrm{mg} / \mathrm{dL})$ & 2.13 & 0.78 & 5.77 & 0.14 & 0.0084 \\
\hline High creatinine $(>1.3 \mathrm{mg} / \mathrm{dL})$ & 1.30 & 0.54 & 3.16 & 0.56 & 0.0074 \\
\hline Low platelets $(<150,000 / \mu \mathrm{L})$ & 2.14 & 0.98 & 4.65 & 0.056 & 0.0089 \\
\hline
\end{tabular}

ASA = American Society of Anesthesiologists; BMI = body mass index.

important to note that even when all patients, including those generally deemed unfit for elective surgery, were included in clinically and statistically driven unplanned readmission and adverse event models, the statistically driven model explained more of the variation and performed better (Appendices 1 and 2). Third, this analysis cannot distinguish between standard TSA and reverse TSA. Fourth, we are limited in our analysis by the use of a large database and its accuracy. However, studies have shown that the ACS NSQIP database, which has its data gathered from patient medical charts, provides better accuracy than claims databases $[15,16]$.

Our analysis of 30-day unplanned readmission found that the statistically driven model (pseudo $\mathrm{R}^{2}=0.046$ ) explained more of the variation in unplanned readmissions than the clinically driven model (pseudo $\mathrm{R}^{2}=0.014$ ), although neither model explained much of the variation. Because neither model explained a great deal of the variation, our results suggest that additional factors are likely impacting unplanned readmission rates. This is important to keep in mind for surgeons who are looking to drastically decrease unplanned readmissions by analyzing the risk factors noted in our models. Although the clinically driven model found no risk factors for 30-day unplanned readmission, the statistical model identified operating time and hypertension requiring medications as independent predictors, both of which are potentially modifiable provider and patient risk factors, respectively. Several studies have reported on risk factors for unplanned readmission after TSA (Table 4) [5, 11, 12, 22]. However, the results are inconsistent (eg, both men and women have been shown to have increased risk of unplanned readmission), and although hypertension confirms a previous known risk factor, others have not noted operating time as a risk factor for unplanned readmission. It is important to note that although our study suggests that upper extremity orthopaedic surgeons should minimize operative time, a confounding scenario in our analysis is that patients who sustained intraoperative complications had longer procedures and subsequent higher readmission risk. Furthermore, our analysis differs from those previously completed because patients unfit for discretionary TSA were removed from the analysis. Although the statistically driven model explained slightly more variation in unplanned readmission, neither explained the variation in unplanned readmission very well. Thus, additional factors 
Table 4. Factors independently associated with an adverse event without inappropriate patients

\begin{tabular}{|c|c|c|c|c|c|}
\hline \multicolumn{6}{|c|}{ Model: Adverse event characteristics selected a priori by clinical expert opinion (logistic regression) } \\
\hline $\begin{array}{l}\text { Area under the receiver operating characteristic curve (c-statistic) } \\
\text { Pseudo } \mathrm{R}^{2} \\
\text { Hosmer-Lemeshow test } \\
\text { Characteristic }\end{array}$ & $\begin{array}{l}0.59 \\
0.0095 \\
0.27 \\
\text { Odds ratio }\end{array}$ & Lower & Upper & $\mathrm{p}$ value & Pseudo $\mathrm{R}^{2}$ (bivariate) \\
\hline Age & 1.03 & 1.00 & 1.05 & 0.05 & 0.0064 \\
\hline ASA classification 3 & 1.21 & 0.77 & 1.91 & 0.40 & 0.0022 \\
\hline BMI & 0.99 & 0.96 & 1.02 & 0.51 & 0.0008 \\
\hline Present smoker & 1.40 & 0.65 & 3.02 & 0.39 & 0.0002 \\
\hline Diabetes mellitus & 1.26 & 0.70 & 2.26 & 0.44 & 0.0010 \\
\hline \multicolumn{6}{|c|}{ Model: Adverse event characteristics $<0.10$ in bivariate analysis (logistic regression) } \\
\hline $\begin{array}{l}\text { Area under the receiver operating characteristic curve (c-statistic) } \\
\text { Pseudo } \mathrm{R}^{2} \\
\text { Hosmer-Lemeshow test } \\
\text { Characteristic }\end{array}$ & $\begin{array}{l}0.66 \\
0.033 \\
0.20 \\
\text { Odds ratio }\end{array}$ & Lower & Upper & $\mathrm{p}$ value & Pseudo $\mathrm{R}^{2}$ (bivariate) \\
\hline Age & 1.03 & 1.01 & 1.06 & 0.018 & 0.0064 \\
\hline Men & 1.64 & 1.05 & 2.57 & 0.031 & 0.0055 \\
\hline Operating time (hours) & 1.27 & 1.07 & 1.52 & 0.007 & 0.0063 \\
\hline High blood urea nitrogen $(>30 \mathrm{mg} / \mathrm{dL})$ & 3.12 & 1.35 & 7.21 & 0.008 & 0.0117 \\
\hline Bleeding disorder & 2.25 & 0.87 & 5.82 & 0.094 & 0.0037 \\
\hline High creatinine ( $>1.3 \mathrm{mg} / \mathrm{dL})$ & 0.98 & 0.42 & 2.26 & 0.96 & 0.0041 \\
\hline
\end{tabular}

ASA = American Society of Anesthesiologists; BMI = body mass index.

not captured by the ACS NSQIP database are likely playing a major role in patients who have unplanned readmission after TSA. However, the fact that the statistically driven model explained more variation and performed better suggests that surgeons should be aware that their clinical intuition may not be as accurate as they expect.

The clinically driven adverse event model (pseudo $\mathrm{R}^{2}=$ 0.0095) explained less of the variation in adverse events than the statistically driven model (pseudo $R^{2}=0.033$ ), although neither model explained a great deal of variation. Many studies have addressed the risk factors for adverse events and found that age, operating time, and men were correlated with increased risk of adverse events $[3,12,28,29]$. Although we also found that men were more likely to have adverse events after a TSA, a previous study found that sex was not correlated with adverse events [10]. Similar to the unplanned readmission analysis, our study differs from others because of our exclusion of patients unfit for elective TSA. Our study further reinforces that statistically driven models explain greater variation in adverse events and perform better than clinically driven models. Because of this finding, surgeons should remain informed of adverse event risk factors determined by large database analyses and consider them in their practices. However, neither the clinically driven model nor statistically driven model explained a great deal of the variation in adverse events. Thus, surgeons should take note that additional risk factors not available in the ACS NSQIP database may play a large role in explaining the variation in adverse events.

Our work reinforces the value of using large databases to estimate risk in addition to clinical intuition. Although neither the clinically derived model nor statistically derived models explain a large amount of the variation in unplanned readmission or adverse events, the statistically driven models still explain more variation and performed better (ie, higher c-statistic). Surgeons could benefit from considering risk factors determined in our analyses and those conducted with other large data sets when planning TSAs. Perhaps most important is the fact that $22 \%$ of patients undergoing TSAs were excluded because of what we would consider contraindications to major discretionary surgery for osteoarthritis. Indeed, models with all patients, including those with risk factors making TSA unwise, explained greater variation and performed better than all other models. However, this is expected given that such risk factors are known to be detrimental to unplanned readmission and adverse event rates. Further exploration could seek to better understand when such surgical interventions are being performed. Checklists and screening procedures can emphasize that discretionary surgery is best for healthy, low-risk patients and provide all patients with 
opportunities for increased comfort and function including improved mood and resiliency. Patients with major medical risk might think surgery is their only hope and be willing to take substantial risks, but it is important that the care team ensure that such a determination is not based on common misconceptions or that it is the expression of stress or distress that will not be well addressed by surgery. In any case, keeping high-risk, arguably inappropriate patients in a risk analysis might produce risk calculators that do not apply as well to the type of patient who is most appropriate for discretionary surgery.

\section{References}

1. American College of Surgeons. User Guide for the 2014 ACS NSQIP Procedure Targeted Participant Use Data File (PUF). 2015. Available at: https://www.facs.org/ /media/files/qualityprograms/nsqip/nsqip_puf_pt_userguide_2014.ashx. Accessed August 5, 2016.

2. American College of Surgeons. 765 ACS NSQIP Hospitals Matching Your Search 2016. Available at: https://www.facs.org/ search/nsqip-participants?allresults. Accessed August 5, 2016.

3. Anthony CA, Westermann RW, Gao Y, Pugely AJ, Wolf BR, Hettrich CM. What are risk factors for 30-day morbidity and transfusion in total shoulder arthroplasty? A review of 1922 cases. Clin Orthop Relat Res. 2015;473:2099-2105.

4. Arundel C, Lam PH, Khosla R, Blackman MR, Fonarow GC, Morgan C, Zeng Q, Fletcher RD, Butler J, Wu WC, Deedwania P, Love TE, White M, Aronow WS, Anker SD, Allman RM, Ahmed A. Association of 30-day all-cause readmission with long-term outcomes in hospitalized older Medicare beneficiaries with heart failure. Am J Med. 2016 Jul 9. [Epub ahead of print].

5. Basques BA, Gardner EC, Toy JO, Golinvaux NS, Bohl DD, Grauer JN. Length of stay and readmission after total shoulder arthroplasty: an analysis of 1505 cases. Am J Orthop (Belle Mead NJ). 2015;44:E268-271.

6. Bhandari M. Evidence-based medicine: why bother? Arthroscopy. 2009;25:296-297.

7. Bozic KJ, Lau E, Kurtz S, Ong K, Rubash H, Vail TP, Berry DJ. Patient-related risk factors for periprosthetic joint infection and postoperative mortality following total hip arthroplasty in Medicare patients. J Bone Joint Surg Am. 2012;94:794-800.

8. Bozic KJ, Lau E, Ong K, Chan V, Kurtz S, Vail TP, Rubash HE, Berry DJ. Risk factors for early revision after primary total hip arthroplasty in Medicare patients. Clin Orthop Relat Res. 2014;472:449-454.

9. Centers for Medicare \& Medicaid Services. Bundled Payments for Care Improvement (BPCI) Initiative: General Information. 2016. Available at: https://innovation.cms.gov/initiatives/ bundled-payments/. Accessed August 6, 2016.

10. Duncan SF, Sperling JW, Morrey BF. Incidence and risk factors for blood transfusion in total elbow arthroplasty. J Shoulder Elbow Surg. 2008;17:961-962.

11. Farng E, Zingmond D, Krenek L, Soohoo NF. Factors predicting complication rates after primary shoulder arthroplasty. J Shoulder Elbow Surg. 2011;20:557-563.
12. Griffin JW, Hadeed MM, Novicoff WM, Browne JA, Brockmeier SF. Patient age is a factor in early outcomes after shoulder arthroplasty. J Shoulder Elbow Surg. 2014;23:1867-1871.

13. Hoonhout LH, de Bruijne MC, Wagner C, Zegers M, Waaijman R, Spreeuwenberg P, Asscheman H, van der Wal G, van Tulder MW. Direct medical costs of adverse events in Dutch hospitals. BMC Health Serv Res. 2009;9:27.

14. Kim SH, Wise BL, Zhang Y, Szabo RM. Increasing incidence of shoulder arthroplasty in the United States. J Bone Joint Surg Am. 2011;93:2249-2254.

15. Lawson EH, Louie R, Zingmond DS, Brook RH, Hall BL, Han L, Rapp M, Ko CY. A comparison of clinical registry versus administrative claims data for reporting of 30-day surgical complications. Ann Surg. 2012;256:973-981.

16. Lawson EH, Zingmond DS, Hall BL, Louie R, Brook RH, Ko CY. Comparison between clinical registry and medicare claims data on the classification of hospital quality of surgical care. Ann Surg. 2015;261:290-296.

17. Lovy AJ, Keswani A, Dowdell J, Koehler S, Kim J, Hausman MR. Outcomes, complications, utilization trends, and risk factors for primary and revision total elbow replacement. J Shoulder Elbow Surg. 2016;25:1020-1026.

18. Matsen FA 3rd, Li N, Gao H, Yuan S, Russ SM, Sampson PD. Factors affecting length of stay, readmission, and revision after shoulder arthroplasty: a population-based study. J Bone Joint Surg Am. 2015;97:1255-1263.

19. Namba RS, Inacio MC, Paxton EW. Risk factors associated with deep surgical site infections after primary total knee arthroplasty: an analysis of 56,216 knees. J Bone Joint Surg Am. 2013;95:775-782.

20. Porter ME. What is value in health care? $N$ Engl J Med. 2010;363:2477-2481.

21. Sackett DL, Wennberg JE. Choosing the best research design for each question. BMJ. 1997;315:1636.

22. Schairer WW, Zhang AL, Feeley BT. Hospital readmissions after primary shoulder arthroplasty. $J$ Shoulder Elbow Surg. 2014;23:1349-1355.

23. Schilling PL, Bozic KJ. Development and validation of perioperative risk-adjustment models for hip fracture repair, total hip arthroplasty, and total knee arthroplasty. J Bone Joint Surg Am. 2016;98:e2.

24. Thorsness R, Shields E, Iannuzzi JC, Zhang L, Noyes K, Voloshin I. Cost drivers after surgical management of proximal humerus fractures in Medicare patients. J Orthop Trauma. 2016;30:262-268.

25. Ubbink DT, Legemate DA. Evidence-based surgery. Br J Surg. 2004;91:1091-1092.

26. Vandenbroucke JP. Observational research and evidence-based medicine: what should we teach young physicians? J Clin Epidemiol. 1998;51:467-472.

27. Virani NA, Williams CD, Clark R, Polikandriotis J, Downes KL, Frankle MA. Preparing for the bundled-payment initiative: the cost and clinical outcomes of total shoulder arthroplasty for the surgical treatment of glenohumeral arthritis at an average 4-year follow-up. J Shoulder Elbow Surg. 2013;22:1601-1611.

28. Waterman BR, Dunn JC, Bader J, Urrea L, Schoenfeld AJ, Belmont PJ Jr. Thirty-day morbidity and mortality after elective total shoulder arthroplasty: patient-based and surgical risk factors. J Shoulder Elbow Surg. 2015;24:24-30.

29. Werner BC, Burrus MT, Begho I, Gwathmey FW, Brockmeier SF. Early revision within 1 year after shoulder arthroplasty: patient factors and etiology. J Shoulder Elbow Surg. 2015;24:e323-330. 